\title{
Preliminary Rheological Characterization of Tyre Derived Crumb Rubber Blended with Kuwaiti Bitumen
}

\author{
Salah E. Zoorob ${ }^{1, *}$ and Suad Al-Bahar ${ }^{1}$ \\ ${ }^{1}$ Construction and Building Materials Program, Kuwait Institute for Scientific Research, P.O. Box \\ 24885 Safat, 13109 Kuwait.
}

\begin{abstract}
This paper presents results from a preliminary laboratory investigation that was carried out in order to determine the suitability of Kuwaiti standard 60/70pen grade bitumen for blending with locally sourced discarded tyre derived crumb rubber. High temperature blending was trialled using three types of truck tyres at $7.5 \%, 15 \%$ and $30 \%$ rubber content by mass of bitumen. A number of basic characterization tests were carried out including; penetration, softening point, viscosity, tensionrelaxation, solvent extraction and glass transition temperature determination. Overall, the results indicate that regardless of the tyre type, blending up to $30 \%$ rubber at the correct temperature and blending time can produce a rheologically improved binder that has potential to withstand the extreme asphalt road surfacing temperatures sustained during the hot summer seasons in the State of Kuwait.
\end{abstract}

\section{Introduction and Project Justification}

Based on published online statistics from the Ministry of Public Works (MPW), the State of Kuwait's total length of main paved roads is slightly in excess of $7518 \mathrm{~km}$ (equivalent to an area of $87,411,674 \mathrm{~km}^{2}$ ). The network suffers from a number of asphalt pavement distress mechanisms including; Fatigue (longitudinal and transverse) cracking, rutting, bleeding, potholes and raveling (loss of stones). The primary causes vary from one site to the other and include; bitumen grade, binder oxidation, bitumen content, incorrect mix design, excessive traffic loading, settlement failure in the lower layers, daily temperature cycles, inadequate compaction, etc.

Climatic conditions in general, and temperature in particular affect pavement design in two ways; first it determines the temperature at which asphalt mix should be designed and/or evaluated and second it indicates the bitumen grade that best works for a temperature zone and traffic load. For pavement design and mix performance purposes, the average maximum pavement design temperature over a consecutive 7-day period is measured at a depth of $20 \mathrm{~mm}$ in the asphalt surfacing, whilst the minimum pavement temperature is recorded on the surface of the pavement which matches the lowest air temperature. For many decades, the minimum and average 7-day maximum air

\footnotetext{
* Corresponding author: $\underline{\text { salah.zoorob@googlemail.com }}$
} 
temperatures in the State of Kuwait had been considered as $-1.6^{\circ} \mathrm{C}$ and $49.9^{\circ} \mathrm{C}$ respectively [1]. In more recent years, Kuwait has been experiencing exceptionally hot summers, as a notable example, on the $20^{\text {th }}$ July 2017 the maximum air temperature in Kuwait City was reported officially at $54^{\circ} \mathrm{C}$. Figure 1 shows the relation between air temperature and recorded temperature at a depth of $20 \mathrm{~mm}$ in pavements in Saudi Arabia, Kuwait and the UAE [2].

There is thus an urgent need to introduce new alternative pavement material compositions capable of replacing currently used conventional asphalt surfacings, with the aim of improving life cycle costing and reducing frequency of maintenance operations.

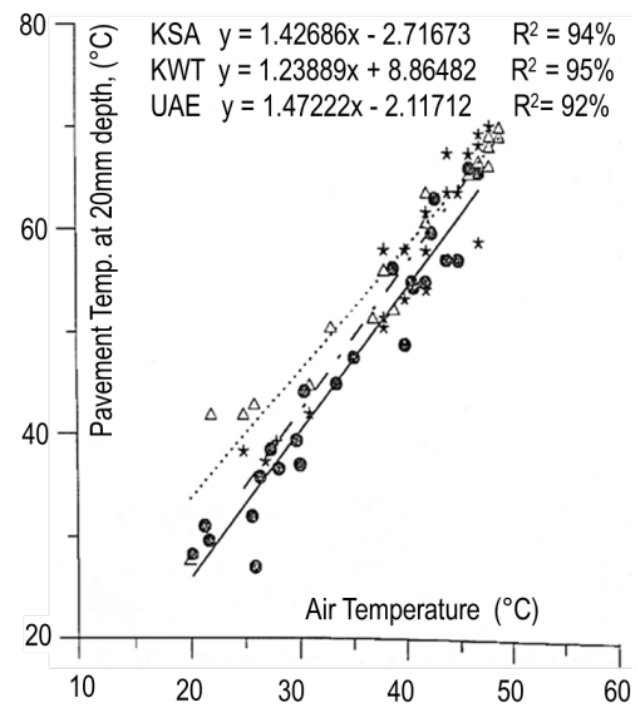

Fig. 1. Examples of relations between air temperature and pavement temperature at a depth of $20 \mathrm{~mm} . \mathrm{KSA}=$ Kingdom of Saudi Arabia, $\mathrm{KWT}=$ Kuwait, $\mathrm{UAE}=$ United Arab Emirates.

Unfortunately for many decades, the only bituminous binder that has been available in use for road construction in Kuwait is a standard 60/70pen grade bitumens which in rheological terms is equivalent to a US Performance Grade PG 64-10. The designation PG 64-10 indicates that the bitumen will "in theory" satisfy performance requirements for a temperature zone that has an average maximum consecutive 7-day pavement temperature of less than $64^{\circ} \mathrm{C}$ and a minimum temperature greater than $-10^{\circ} \mathrm{C}$.

In response, in 2017, the MPW instructed all asphalt plant operators in Kuwait to upgrade their existing hot mix asphalt (HMA) production facilities to accommodate the handling the incorporation of polymer modified bitumens (PMBs) and additionally to upgrade their laboratory testing facilities to be capable of conducting the latest US Superpave binder testing and characterization [3].

In parallel, the Construction \& Building Materials Program at the Kuwait Institute for Scientific Research (KISR) is also actively involved in addressing the problems of asphalt surfacing deterioration and has proposed a collaborative project with MPW to investigate the use of waste tire derived crumb rubber to enhance the rheological properties of existing conventional Kuwaiti 60/70 pen grade bitumen.

An optimized rubber-bitumen blend will next be used in combination with locally sourced aggregate in the manufacture of a high performance rubberized-hot mix asphalt (HMA). The rubberized-HMA will be subsequently used in the construction of a $5 \mathrm{~cm}$ thick wearing course (1 km stretch) as part of routine maintenance operations. 
The long term performance of this trial section carrying the medium/heavy traffic loading prevalent on the roads of Kuwait under local weather conditions will be monitored and evaluated. This road trial will be designed to demonstrate and assess the benefits of rubberized HMA technology, in particular with respect to alleviating the three main forms of distress on Kuwaiti roads, namely; severe rutting, fatigue cracking and moisture induced stripping, which in turn should directly influence the frequency and overall cost of road maintenance operations.

It is interesting to note that in Kuwait the largest waste tyre dump located at "Rehaya" holds approximately 28 million whole tyres in a chaotic fashion where by some of the old burial pits are in excess of $20 \mathrm{~m}$ deep. Contractors are currently actively recovering the buried tyres and rough cutting them into large pieces which are being transported and stored to another site at "Salmi". Furthermore, Kuwait continues to add between 5000 to 6000 discarded tyres to the dump per day. The large quantities of crumb rubber that can potentially be utilized in the bitumen upgrading process will be derived from discarded waste tires with obvious benefits from an environmental perspective. As an example, to replace only the upper layer (i.e. $5 \mathrm{~cm}$ asphalt wearing course) of a single lane on a damaged road using Rubberized-HMA, would consume approximately 4.5 tons of crumb rubber per $1 \mathrm{~km}$ length of road (equivalent to 100 discarded truck tyres or 500 car tyres).

\section{Background to Rubberized-Hot Mix Asphalt}

Rubberized-HMA is a process of blending crumb rubber produced from recycled waste tires into hot bitumen to produce an extremely resilient, high performance, modified binder (Rubberized-bitumen) that is used in road paving operations. The rubberized-HMA process originated in the United States in the late 1960s, and since that time a large collection of historical data has been amassed that highlights crumb rubber's enhancement of mixture performance including; improved rutting resistance, thermal cracking resistance, reflective crack resistance and resistance to load induced fatigue cracking. Other benefits reported include reduction in frequency of maintenance operations, a smooth ride, good skid resistance, and noise reduction $[4,13,15]$.

Sacramento County initiated a detailed 6 year study (starting in 1993) to investigate the benefits of rubberized asphalt surfacings on road noise. The performance of rubberized asphalt surfacings was compared to a conventional asphalt overlay. The conclusions of the study showed an average 4 decibel $(\mathrm{dB})$ reduction in traffic noise levels of the rubberized sections as compared to the conventional asphalt overlay [5]. This degree of noise attenuation is significant, as it represents a $60 \%$ reduction (which is clearly perceptible) in traffic noise energy. It was also noted that the effectiveness of rubberized asphalt in reducing traffic noise levels would be highest on roadways with relatively low percentages of heavy duty trucks, as truck engine and exhaust stack noise is not believed to be substantially affected by rubberized paving.

In one large study conducted by the advisory board of the Rubber Asphalt Foundation (RAF), evidence was presented to conclusively prove the suitability of recycled tire rubberized-bitumens as direct substitutes to Polymer Modified Bitumens (PMBs) such as Styrene Butadiene Styrene (SBS), and furthermore it was shown that rubberized-bitumens achieved the same performance grading specifications as the PMBs [6, 14].

\subsection{Additional Costs Associated with Rubberized-HMA}

Generally, factors that impact cost of rubberized-HMA include: established usage of product, capital costs, increased material costs, and increased operational costs. Additional factors that influence individual project costs are project size, patent royalty fees, and the contractor's "fear factor" associated with unknown impacts on plant processes such as 
increased fuel costs for higher temperatures, plant/equipment damage, down time changing between rubber modified and unmodified jobs [9]. The actual mixing process of the rubberized-HMA at the hot mix asphalt plant is the same as for conventional HMA [10].

Components that need to be added at the asphalt plant are; rubber storage, rubber feed, heated blending tanks (approx. $190^{\circ} \mathrm{C}$ ), and (optional) a heated reaction tank (approx. $177^{\circ} \mathrm{C}$ ). A separate connection from the plant's standard bitumen feed is made to the pug mill mixer. This allows the plant to produce other mixes without unnecessary delays. Rubber storage requirements will depend upon the method used for adding the rubber. Bagged rubber usually comes in $10-15 \mathrm{~kg}$ paper bags on pallets which are added to the tanks manually. Bulk rubber can be stockpiled (covered) and fed into the tanks via loading buckets, hopper and conveyer systems [9].

Hauling of the rubberized-HMA is the same as for conventional HMA except that soapy water or a silicone emulsion should be used for a releasing agent. Diesel or solvents should not be used. This difference should result in no cost differential between two mix types. The placement and compaction of rubberized-HMA is generally the same as for conventional HMA, though the placement temperature for rubberized-HMA is somewhat higher than for conventional HMA, and furthermore, pneumatic rollers cannot be used for compacting rubberized-HMA. Instead, vibratory (for breakdown rolling) and static steel wheel rollers should be used [10].

In 1993, at the request of US Senate staff, the American Association of State Highway and Transportation Officials (AASHTO) was requested to provide information on cost experience by the states with crumb rubber modified hot mix asphalt projects, based on actual project costs in that year. The responses from 25 states were analyzed and in conclusion, it was observed the average cost of rubberized-HMA trials on 66 actual projects, over the period Jan. to Sept. 1993, was about $67 \%$ higher than the average cost of conventional HMA projects [11].

In the United States of America, there are currently 25 states which legislate the use of recycled tire rubber in asphalt pavement mixtures for improving road performance and for minimizing the frequency of road maintenance operations and related costs. A standard practice guide, or manual, aimed at engineers, researchers, students and technicians, has been published in 2012 by the Rubber Pavement Association (RPA), to provide an overview of all the necessary basic information regarding the design and use of Rubberized-HMA [7]. In addition to the United States, rubberized-HMA has been successfully used in Portugal, South Africa, Spain, China, Poland, Saudi Arabia, Mexico, Russia, Brazil, Puerto Rico, Italy, and the Czech Republic [8].

The experimental data presented in this paper are the results of preliminary laboratory trials conducted at KISR to evaluate the compatibility of the locally produced discarded tire derived crumb rubber with the standard Kuwaiti 60/70pen bitumen and the effects on rheological properties of the resultant rubber-bitumen blend.

\section{Materials used and Sample Preparation}

A preliminary program was devised by KISR to study the modifying effects of ground tyre rubber from 3 types of discarded Truck tyres, namely; Goodyear, Toyo and Bridgestone. A conventional air blown 60/70pen paving grade bitumen was used (penetration $=64 \mathrm{dmm}$, Softening Point $=49.8^{\circ} \mathrm{C}$, equivalent to PG 64-10).

Mixing of ground rubber in bitumen was accomplished in a one liter metal container, closed with a lid but with openings for a stirrer, a thermometer and rubber feed. Stirring was carried out using a 4-bladed propeller driven by a $0.75 \mathrm{~kW}$ motor. Heat was applied by a standard thermostatically controlled hot plate. The sides of the container were covered by a thick glass wool insulation. The bitumen was continuously stirred to prevent any local overheating. Ground rubber was added slowly, keeping the temperature of the contents 
within $5 \%$ of the desired setting. Mixer speeds trialed were 250 and $1000 \mathrm{rpm}$, mixing temperatures trialed were $150^{\circ} \mathrm{C}, 175^{\circ} \mathrm{C}$ and $200^{\circ} \mathrm{C}$, whilst total mixing time was fixed at 1.5 hours to produce a visually homogeneous product. Mixing temperatures higher than $200^{\circ} \mathrm{C}$ are not recommended for a number of reasons including; higher risk of rubber decomposition (devulcanization), excessive oxidative hardening of the binder, excessive fumes being generated, and increased energy consumption during the blending process. At the other end of the scale, lowering the mixing temperature excessively causes the viscosity to become unacceptably high. In this investigation, the amounts of crumb rubber added to the bitumen were $7.5 \%, 15 \%$ and $30 \%$ by mass of bitumen.

\section{Rheological Tests Conducted}

Viscometry - This test was performed in a Hake rotational viscometer using couette cylinders (sensor type SV II) and measuring head (Type ML 500). Measurements were carried out at $60^{\circ} \mathrm{C}, 80^{\circ} \mathrm{C}, 100^{\circ} \mathrm{C}, 135^{\circ} \mathrm{C}$ and $150^{\circ} \mathrm{C}$ and across the range from $0-100 \%$ of torque. The selected temperature range for viscosity determinations was intended at the lower end to cover the service temperatures experienced by road surfaces in summer in Kuwait, whilst at the upper end, the test temperatures cover the range normally employed for mixing and compaction of hot mix asphalt using the Marshall method of mix design.

Penetration and Softening Point Tests - Penetration test was carried out on all rubberbitumen blends in accordance with ASTM D5 at test temperatures of $5^{\circ} \mathrm{C}, 10^{\circ} \mathrm{C}, 25^{\circ} \mathrm{C}$, $35^{\circ} \mathrm{C}$ and $45^{\circ} \mathrm{C}$, whilst the Softening Point test was carried out in accordance with ASTM D36.

Toughness - This test provides a rough indication of the amount of energy needed to extend a sample of binder. Tensile loading was carried out using an Instron hydraulic machine set at a cross-head speed of $50 \mathrm{~mm} / \mathrm{min}$. Testing was carried out at $10^{\circ} \mathrm{C}$ and $25^{\circ} \mathrm{C}$ using rubber-bitumen specimens cast to a size of $(40 \mathrm{~mm} \times 12 \mathrm{~mm} \times 4 \mathrm{~mm})$. The area under the load-elongation plot was defined as toughness.

Tension-Relaxation - The equipment used, specimen dimensions and tensile loading speed were identical to the toughness test described earlier. Specimens were loaded at 50 $\mathrm{mm} / \mathrm{min}$ until the sample reached 1.5 times its original length and the strain was maintained constant whilst load relaxation was recorded for a period of 1 minute. Specimens were initially conditioned for 2 hours in a water bath at $25^{\circ} \mathrm{C}$ and each test completed in under 3 minutes.

Extraction in Solvent - Selected rubberized-bitumen samples were extracted using nheptane in order to separate the unreacted rubber from the bitumen phase.

Glass Transition Temperature - A Dupont DSC cell was used to measure the glass transition temperature of rubberized-bitumen samples. The specimens were initially cooled to $-70^{\circ} \mathrm{C}$ and heated in the $\mathrm{DSC}$ cell at a rate of $5^{\circ} \mathrm{C} / \mathrm{min}$. The resulting enthalpytemperature curve was used to detect the glass transition temperatures.

\section{Results and Analysis}

\subsection{Effect of Crumb Rubber Type and Content on Rheology}

Softening point (S.P.) data for mixes prepared at $250 \mathrm{rpm}$ and $1000 \mathrm{rpm}$ indicated that at each of the 3 crumb rubber concentrations (i.e. $7.5 \%, 15 \%, 30 \%$ ), only a maximum of $10 \%$ difference in the S.P. of the binder could be attributed to the difference in formulation of the rubber compounds between the 3 manufacturers (i.e. Toyo, Bridgestone and Goodyear). As can be observed in Figure 2, a doubling of the S.P. is obtained by blending $30 \%$ rubber with the base bitumen. For paving applications in Kuwait, a SP. of up to $90^{\circ} \mathrm{C}$ should be 
more than adequate to combat rutting distresses, and this value is exhibited by mixes $(25 \%$ to $30 \%$ rubber) prepared at $200^{\circ} \mathrm{C}$ and $250 \mathrm{prm}$.

The slope of the penetration-temperature plots is a measure of the temperature susceptibility of the binder (example Figure 3). At any single rubber-bitumen concentration, a maximum of $15 \%$ difference in the slopes was observed between the different crumb rubber types. By blending $30 \%$ crumb rubber into the bitumen, the temperature sensitivity of the base bitumen can be effectively reduced by half.

Increasing the mixer speed produces a better dispersion of crumb rubber in the bitumen and a more uniform product with less variation in temperature susceptibility (i.e. flatter slope of viscosity-temperature lines) results. Within experimental error, blends prepared at $1000 \mathrm{rpm}$ and $200^{\circ} \mathrm{C}$, showed almost no differences in the temperature susceptibility between the blends made with different crumb rubber types.

The data presented in Figure 4 demonstrates that in the temperature range of $60^{\circ} \mathrm{C}$ to $80^{\circ} \mathrm{C}$ (i.e. expected maximum road surface temperatures), at $15 \%$ rubber content the viscosity of the rubber-bitumen blend increases by approximately 20 times compared to the base bitumen, whilst at $30 \%$ rubber content the increase is almost 1000 times. At the upper end of the temperature spectrum (mixing at the asphalt plant and site compaction temperatures), a $30 \%$ rubber addition causes the viscosity to increase by approximately 100 times.

Figures 6 and 7 present examples of direct comparison of the measured rotational viscometer torque values (proportional to binder viscosity) versus rotor speed (proportional to shear rate) of the $60 / 70$ pen base bitumen in comparison to the $30 \%$ rubber-bitumen blend (Goodyear truck tire graded crumb) at a range of test temperatures. The results from Figures 6 and 7 highlight two rheological trends: a- the significant increase in viscosity at all test temperatures as a result of blending crumb rubber into the base bitumen, and b- the Newtonian behavior of the base bitumen at all test temperatures in comparison to the shear thinning behavior of the rubber-bitumen blends.

\subsection{Effect of crumb rubber size on rheological properties}

It was observed that the softening point temperature increases with increasing particle size, especially at higher rubber concentrations (e.g. 30\%), see Figure 2. Doubling the crumb rubber size (from $300 \mu \mathrm{m}$ to $600 \mu \mathrm{m}$ ) was shown to increase the viscosity by a factor of between 5 to 8 at service temperatures $\left(60^{\circ} \mathrm{C}\right.$ to $\left.80^{\circ} \mathrm{C}\right)$, whilst at the highest test temperatures $\left(135^{\circ} \mathrm{C}\right.$ to $\left.150^{\circ} \mathrm{C}\right)$ the factor reduces to less than 2 , see Figure 5 .

Based on the results thus far, one would be inclined to favour a bigger rubber particle size, e.g. $600 \mu \mathrm{m}$ as opposed to $300 \mu \mathrm{m}$. However, the tension-toughness results show higher toughness (over $50 \%$ higher) and ductility (100\% greater) for the smaller particle size, though the maximum load carrying capacity has been decreased by approximately $30 \%$ (see last 2 rows of Table 1). Additionally, the stress-relaxation properties of the binder do not seem to be affected by the rubber size (see last 2 rows of Table 2).

Thus to optimize the effects of rubber particle size on binder properties, it was recommended that the particle sizes in the range of 300-600 $\mu \mathrm{m}$ should constitute the dominant part of the particle size distribution (preferably in the ratio of 2:1, 300 $\mu \mathrm{m}$ to $600 \mathrm{um}$ ) which was roughly in line with the particle size distribution of the graded crumb rubber samples used in this investigation as shown in Table 3.

\subsection{Liquid Extraction Results}

When blending trials were carried out at $300^{\circ} \mathrm{C}$, all the crumb rubber became disintegrated and dissolved into the base bitumen as evidenced by soxhlet extraction with $(90 \%$ benzene $/ 10 \%$ isopropanol) which did not produce any rubber residue. At mixing temperatures under $250^{\circ} \mathrm{C}$, all of the rubber in the rubber-bitumen blend was recoverable. 
It is well understood in polymer science that elastomers, as crosslinked products (e.g. tyre rubber), are insoluble in liquids, as far as the crosslinks are not destroyed. They show however, a greater or lesser volume increase, the extent of which is a function of compatibility factors, and this increases with time until an equilibrium swelling rate has been attained. This absorption of liquid is associated with three-dimensional expansion of the network structure. Loosening of the cohesive bonds causes a large number of mechanical properties to deteriorate, e.g. tensile strength, tear propagation strength and hardness. If no material extraction takes place by virtue of the swelling process, then the original property state is obtained after full-scale reversal of the swelling. This seldom occurs, however, since the swelling media, e.g. stabilizers, antioxidants and plasticizers, are partially dissolved out. This causes changes in ageing properties and hardness etc. after swelling and subsequent reversal of the swelling [12].

On the other hand, non-crosslinked rubber (gum rubber) can swell in certain compatible solvents until it loses all cohesive strength and goes into solution. A swelling equilibrium does not occur in this process. The necessary condition for this process is the higher osmotic pressure that the solvent exacts on the polymer, compared to the forces that hold the molecules of the high polymer together [12].

\subsection{Glass Transition Temperature}

Examples of glass transition temperatures $\left(\mathrm{T}_{\mathrm{g}}\right)$ of various rubber-bitumen blends are shown in Table 4. As both bitumen and tire derived crumb rubber are composed of complex molecules of various types and molecular weights, the glass transition temperatures obtained were not very sharp but rather broad, and at times not clearly defined.

An increase in $\mathrm{T}_{\mathrm{g}}$ (from $-5^{\circ} \mathrm{C}$ to $+10^{\circ} \mathrm{C}$ ) was observed as a result of simply heating and stirring the base bitumen at $200^{\circ} \mathrm{C}$ for 1.5 hours, which reflects the oxidative hardening reactions that occur during hot handling of bitumens. By blending 30\% graded crumb rubber, at the very least it is possible to reduce the $\mathrm{T}_{\mathrm{g}}$ (the temperature at which the binder is liable to experience brittle fracture under applied external stress) from +10 to $-18^{\circ} \mathrm{C}$. This is a huge benefit in terms of retarding the hardening process and permitting the use of this product at sub-zero ambient temperatures (whilst maintaining flexibility and resilience).

Since hardening of bitumens result from oxidative reactions accompanied by loss of volatile chemical fractions, it may be hypothesized that hardening of the binder may be retarded by the absorption of these lighter fractions and the presence of anti-oxidant and UV stabilizers in the tyre formulations.
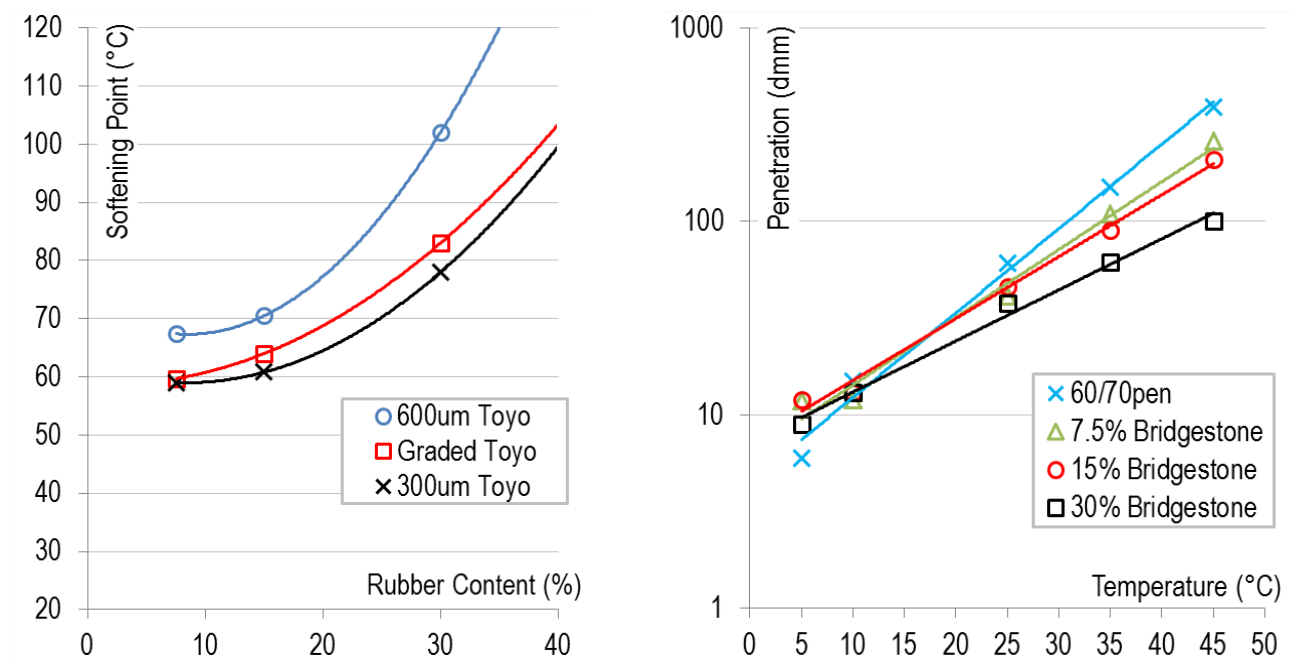
Fig. 2. Softening Point v.s. rubber content for 3 sizes of Toyo crumb rubber.

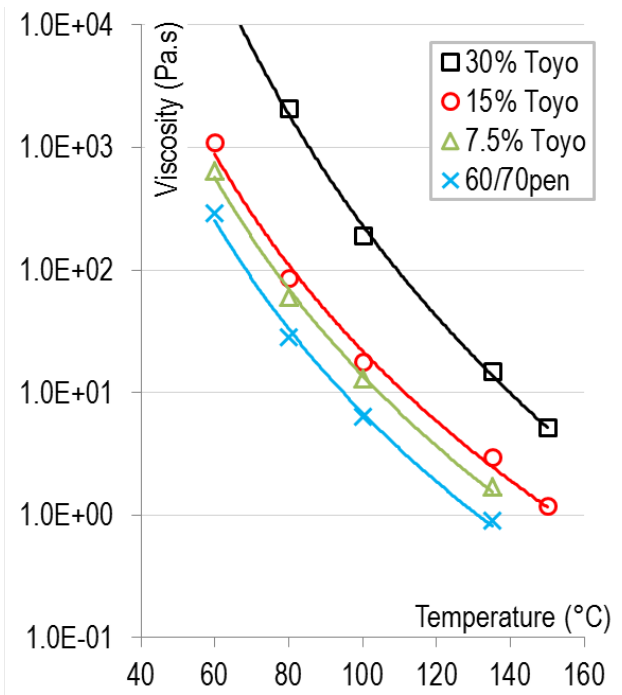

Fig. 4. Rotational viscosity versus test temperature for various rubber-bitumen blend concentrations.

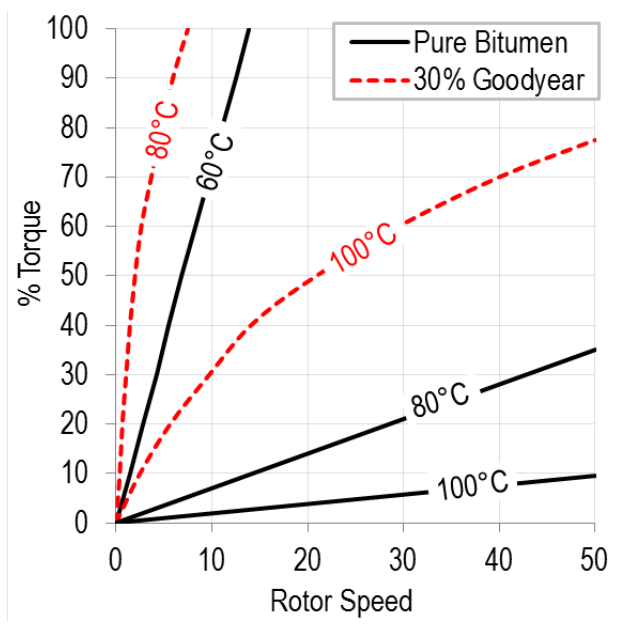

Fig. 6. Shear stress v.s. shear rate relationships for 60/70pen base bitumen and $30 \%$ rubberbitumen blend at $60^{\circ} \mathrm{C}, 80^{\circ} \mathrm{C}, 100^{\circ} \mathrm{C}$.
Fig. 3. Penetration values of blends at various rubber contents conducted at a range of test temperatures.

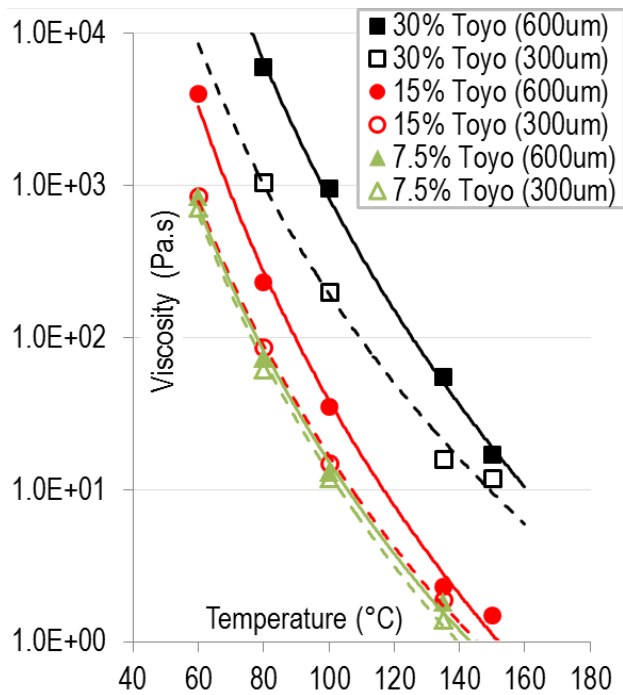

Fig. 5. Rotational viscosity versus test temperature for various rubber-bitumen concentrations and rubber sizes.

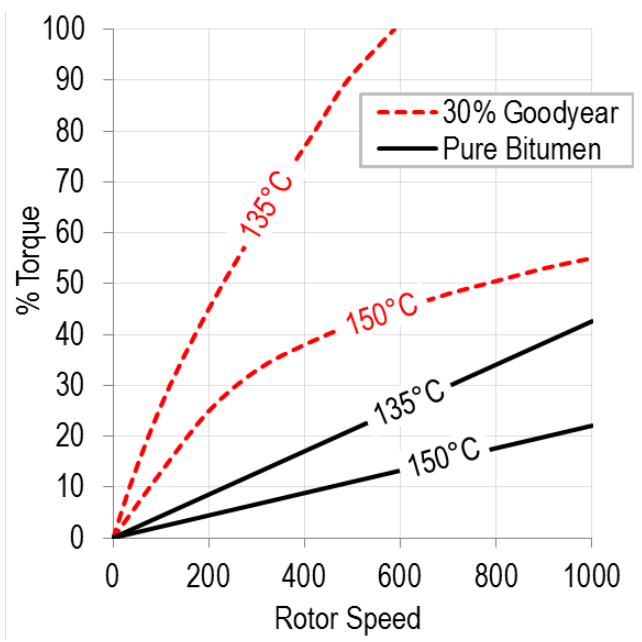

Fig. 7. Shear stress v.s. shear rate relationships for 60/70pen base bitumen and 30\% rubberbitumen blend at $135^{\circ} \mathrm{C}$ and $150^{\circ} \mathrm{C}$. 
Table 1. Tension toughness at $25^{\circ} \mathrm{C}$ for rubber modified airblown 60/70pen bitumen binder.

\begin{tabular}{|c|c|c|c|}
\hline Binder Type & $\begin{array}{c}\text { Max. Load } \\
\text { (g) }\end{array}$ & $\begin{array}{c}\text { Elongation at } \\
\text { Break (cm) }\end{array}$ & $\begin{array}{c}\text { Toughness } \\
\text { (meter grams) }\end{array}$ \\
\hline Pure airblown 60/70pen bitumen & 0.58 & $300+$ & 0.03 \\
\hline $\begin{array}{c}30 \% \text { Toyo Truck Tyre, prepared at } \\
150^{\circ} \mathrm{C}, 250 \text { RPM }\end{array}$ & 5.83 & 100 & 0.47 \\
\hline $\begin{array}{c}30 \% \text { Toyo Truck Tyre, prepared at } \\
175^{\circ} \mathrm{C}, 250 \text { RPM }\end{array}$ & 5.00 & 90 & 0.34 \\
\hline $\begin{array}{c}30 \% \text { Toyo Truck Tyre, prepared at } \\
200^{\circ} \mathrm{C}, 250 \text { RPM }\end{array}$ & 6.74 & 95 & 0.52 \\
\hline $\begin{array}{c}30 \% \text { Toyo Truck Tyre, Size 300 } \mu \mathrm{m}, \\
\text { prepared at } 200^{\circ} \mathrm{C}, 1000 \text { RPM }\end{array}$ & 4.12 & 180 & 0.64 \\
\hline $\begin{array}{c}30 \% \text { Toyo Truck Tyre, Size } 600 \mu \mathrm{m}, \\
\text { prepared at } 200^{\circ} \mathrm{C}, 1000 \mathrm{RPM}\end{array}$ & 7.55 & 80 & 0.40 \\
\hline
\end{tabular}

Table 2. Tension relaxation at $25^{\circ} \mathrm{C}$ for rubber modified air blown $60 / 70$ pen bitumen binder.

\begin{tabular}{|c|c|c|c|}
\hline Binder Type & $\begin{array}{l}\text { Initial Load } \\
\text { L (g) }\end{array}$ & $\begin{array}{l}\text { Final Load } \\
\text { F (g) }\end{array}$ & $\begin{array}{l}\begin{array}{l}\text { Unrelaxed Load } \\
(\mathrm{F} / \mathrm{L} \times 100) \quad(\%)\end{array} \\
\end{array}$ \\
\hline Pure airblown 60/70pen bitumen & 0.58 & 0.019 & 3 \\
\hline $\begin{array}{c}30 \% \text { Toyo Truck Tyre, prepared at } \\
150^{\circ} \mathrm{C}, 250 \mathrm{RPM}\end{array}$ & 5.83 & 2.05 & 35 \\
\hline $\begin{array}{c}30 \% \text { Toyo Truck Tyre, prepared at } \\
175^{\circ} \mathrm{C}, 250 \mathrm{RPM}\end{array}$ & 4.95 & 1.76 & 36 \\
\hline $\begin{array}{l}30 \% \text { Toyo Truck Tyre, prepared at } \\
200^{\circ} \mathrm{C}, 250 \mathrm{RPM}\end{array}$ & 4.51 & 1.47 & 33 \\
\hline $\begin{array}{c}30 \% \text { Toyo Truck Tyre, Size } 300 \mu \mathrm{m}, \\
\text { prepared at } 200^{\circ} \mathrm{C}, 1000 \mathrm{RPM}\end{array}$ & 1.67 & 0.58 & 35 \\
\hline $\begin{array}{l}30 \% \text { Toyo Truck Tyre, Size } 600 \mu \mathrm{m}, \\
\text { prepared at } 200^{\circ} \mathrm{C}, 1000 \mathrm{RPM}\end{array}$ & 7.45 & 2.35 & 32 \\
\hline
\end{tabular}

Table 3. Gradation curve for crumb rubber (Good Year truck tyre sample).

\begin{tabular}{|c|c|c|c|}
\hline Sieve Size & \% Passing & Sieve Size & \% Passing \\
\hline $2.36 \mathrm{~mm}$ & 98.7 & $250 \mu \mathrm{m}$ & 16.8 \\
\hline $1.18 \mathrm{~mm}$ & 94.8 & $180 \mu \mathrm{m}$ & 9.5 \\
\hline $600 \mu \mathrm{m}$ & 74.3 & Pan & 0.0 \\
\hline $300 \mu \mathrm{m}$ & 27.2 & & \\
\hline
\end{tabular}

Table 4. Glass Transition Temperatures of Various Rubber Asphalt Blends.

\begin{tabular}{|l|c|}
\hline \multicolumn{1}{|c|}{ Binder Type } & $\mathbf{T}_{\mathbf{g}}\left({ }^{\circ} \mathbf{C}\right)$ \\
\hline Pure airblown 60/70pen bitumen & -5 \\
\hline Pure airblown 60/70pen bitumen after mixing at $200^{\circ} \mathrm{C}, 250 \mathrm{RPM}, 1.5 \mathrm{~h}$ mixing & +10 \\
\hline $30 \%$ Toyo Truck Tyre, prepared at $200^{\circ} \mathrm{C}, 250 \mathrm{RPM}, 1.5 \mathrm{~h}$ mixing & -18 \\
\hline $30 \%$ Toyo Truck Tyre, prepared at $175^{\circ} \mathrm{C}, 250 \mathrm{RPM}, 1.5 \mathrm{~h}$ mixing & -25 \\
\hline
\end{tabular}




\begin{tabular}{|l|l|}
\hline $30 \%$ Toyo Truck Tyre, prepared at $150^{\circ} \mathrm{C}, 250 \mathrm{RPM}, 1.5 \mathrm{~h}$ mixing & -28 \\
\hline $30 \%$ Toyo Truck Tyre $(300 \mu \mathrm{m})$, prepared at $200^{\circ} \mathrm{C}, 1000 \mathrm{RPM}, 1.5 \mathrm{~h}$ mixing & -15 \\
\hline $30 \%$ Toyo Truck Tyre $(600 \mu \mathrm{m})$, prepared at $200^{\circ} \mathrm{C}, 1000 \mathrm{RPM}, 1.5 \mathrm{~h}$ mixing & -20 \\
\hline
\end{tabular}

\section{Conclusions}

Based on the experimental error expected from softening point, penetration and rotational viscometry tests, it was observed the source of crumb rubber (Toyo, Bridgestone, Goodyear) had no significant effect on the rheological properties of the binder.

For paving applications in Kuwait, a softening point approaching $90^{\circ} \mathrm{C}$ would be more than adequate to combat rutting distresses and this was exhibited by mixes containing between $25 \%$ to $30 \%$ rubber prepared at $200^{\circ} \mathrm{C}$ and $250 \mathrm{rpm}$. In this range of rubber content, the viscosity of the rubber-bitumen blend at the maximum expected road temperatures in summer is increased by approximately 20 times whilst the temperature sensitivity of the base bitumen is reduced by half.

The glass transition temperature of a $30 \%$ rubber-bitumen blend was approximately $15^{\circ} \mathrm{C}$ higher than the original bitumen. The preferred crumb rubber particle size is between 300 to $600 \mu \mathrm{m}$, whilst the maximum recommended rubber-bitumen blending temperatures is $250^{\circ} \mathrm{C}$. Overall, blending discarded tyre derived crumb rubber with bitumen at high temperature to produce a rubberized-bituminous binder has great potential to improve the rheological properties of the standard 60/70pen grade Kuwaiti bitumen.

\section{References}

1. H.K. Al-Abdul Wahhab, I.M. Asi, I.A. Dubabe and M.F. Ali, Development of performance-based bitumen specifications for the Gulf countries, Construction and Building Materials, 11, 1, pp. 15-22 (1997).

2. F. Bissada, Asphalt Pavement Temperature Related to Kuwait Climate, HRR 404, Transportation Research Board, Washington D.C., pp. 71-85 (1972).

3. Asphalt Institute, MS-25 Asphalt Binder Testing Manual, $3^{\text {rd }}$ edition, ISBN: 9781934154649.

4. M. Cope, Performance and Economic Benefits of Paving with Asphalt Rubber; Rubber Asphalt Foundation (1985)(www.ra-foundation.org)

5. Sacramento County Department of Environmental Review and Assessment, Report on the Status of Rubberized Asphalt - Traffic Noise Reduction, Nov. (1999).

6. J. D'Angelo, Rubberized Asphalt Study, Recycled Tire Rubber in Place of P.G. Polymer Modified Asphalt, Whitepaper issued by Rubberized Asphalt Foundation (2013).

7. G. Way, K. Kaloush, and K. Biligiri, Consulpav Int. and Arizona State University. Asphalt-Rubber Standard Practice Guide. Rubber Pavement Association (2012).

8. Phoenix Industries, LLC, 1988. 300 E. Delhi Ave. N. Las Vegas, Nevada, 89032, USA. www.PhoenixIndustries.com (1988).

9. M. Stroup-Gardiner, Cost Factors, Federal Highway Administration, Crumb Rubber Modifier Workshop, Denver, Colorado, March (1993).

10. G.R. Morris, K.R. Hansen, Cost Considerations of Asphalt-Rubber Hot Mix, www.rubberpavements.org/ARTIC/Cost/ARTIC_Cost_RPA_A1595.html (1993).

11. American Association of State Highway and Transportation Officials (AASHTO) CRM HMA Cost Survey, Sept. (1993).

12. W. Hofmann, Rubber Technology Handbook, Hanser Pub., ISBN 3446-14895-7 (1989).

13. D. Lo Presti, Recycled Tyre Modified Bitumens for road asphalt mixtures : A literature review, Construction and Building Materials, 49, pp. 863-881 (2013).

14. B. Bairgi, S.M. Hossain, R. D. Henrix, Investigation of rheological properties of asphalt rubber toward sustainable use of scrap tires, (IFCEE 2015), ASCE, pp. 359-368. 
15. T. Ma, H. Wang, L. He, and J. Chen, Property characterization of asphalt binders and mixtures modified by different crumb rubbers, J. Mater. Civ. Eng.,29, 7, (2017). 